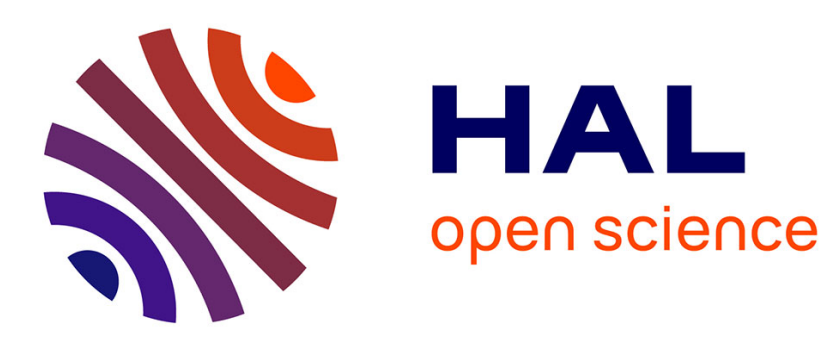

\title{
Experimental and numerical determination of the dynamic fracture energy of concrete
}

\author{
J. van Doormaal, J. Weerheijm, L. Sluys
}

\section{To cite this version:}

J. van Doormaal, J. Weerheijm, L. Sluys. Experimental and numerical determination of the dynamic fracture energy of concrete. Journal de Physique IV Proceedings, 1994, 04 (C8), pp.C8-501-C8-506. 10.1051/jp4:1994878 . jpa-00253439

\section{HAL Id: jpa-00253439 https://hal.science/jpa-00253439}

Submitted on 1 Jan 1994

HAL is a multi-disciplinary open access archive for the deposit and dissemination of scientific research documents, whether they are published or not. The documents may come from teaching and research institutions in France or abroad, or from public or private research centers.
L'archive ouverte pluridisciplinaire HAL, est destinée au dépôt et à la diffusion de documents scientifiques de niveau recherche, publiés ou non, émanant des établissements d'enseignement et de recherche français ou étrangers, des laboratoires publics ou privés. 


\title{
Experimental and numerical determination of the dynamic fracture energy of concrete
}

\author{
J.C.A.M. van Doormaal, J. Weerheijm and L.J. Sluys* \\ TNO Prins Maurits Laboratory, P.O. Box 45, 2280 AA Rijswijk, The Netherlands \\ * Delft University of Technology, Department of Civil Engineering, P.O. Box 5048, 2600 GA Delft, \\ The Netherlands
}

\begin{abstract}
Resumé: Dans un programme expérimental, des essais de traction rapides ont été exécutés sur une barre d'Hopkinson. Dans la plupart des spécimens un trait de scie a été fait. L'objectif était la détermination de l'énergie de fracture dynamique du béton. Les résultats ont été comparés avec des essais quasi-statiques. Pour distinguer le comportement du materiau et de la construction, les expériences ont eté simulées numériquement. Cela a resulté à l'observation que l'énergie de fracture dynamique est approximativement équivalent à l'énergie de fracture statique.
\end{abstract}

\begin{abstract}
In an experimental programme, impact tensile tests were performed on notched and unnotched specimens in a Split Hopkinson Bar apparatus to determine the dynamic fracture energy of concrete. The results have been compared to static experiments. In order to distinguish structural and material response the experiments were numerically simulated. That resulted in the observation that the dynamic fracture energy and the static fracture energy are approximately equal.
\end{abstract}

\section{INTRODUCTION}

Nowadays, engineers have advanced computer codes at their disposal for the design of protective structures. These computer codes offer the opportunity to calculate the load distribution in and the response of a structure, caused by an explosive or impact load. The application of these advanced codes only makes sense when accurate constitutive relations for the dynamic material behaviour are available, which generally differs from the static behaviour.

Concrete is often used in protective structures. However, despite many applications the knowledge with regard to the dynamic behaviour of concrete is still limited. From many studies in preceding years (see for instance [1], [2], [3] and [4]) it is generally known that a higher loading rate results in a higher strength, but the influence of the loading rate on the deformation capacity is more questionable. Not many studies were focused on this subject. And furthermore the results of the few studies in which the dynamic deformation capacity or fracture energy was examined do not always correspond.

In our present study, we focus on the dynamic deformation capacity and fracture energy because in our opinion this is, next to the strength, an important parameter. The protection, a structure offers, strongly depends on its failure mode. Tensile strength and fracture energy can affect the failure mode.

Uniaxial impact tensile tests have been performed by TNO-PML and DUT in a Split Hopkinson Bar apparatus on notched specimens in order to determine the influence of the loading rate on the fracture energy. Additionally, numerical simulations of the tests were carried out, with use of which material and structural response could be distinguished. The results of both experiments and calculations are discussed in this paper.

\section{STATE OF THE ART}

A complete review of the state of the art is outside the scope of this paper and will not be presented here. We will confine ourselves to giving the reader notice of the general opinion with regard to the dynamic deformation capacity of concrete. 
The common opinion ([5] and [6]) is that the deformation capacity of concrete under uniaxial loading increases due to rate effects. Figure 1, determined by Körmeling [5] from impact tests with a Split Hopkinson Bar apparatus, illustrates this influence of the strain rate. It shows an increase in strength and an increase in absorbed energy, which is equivalent to the area underneath the curve.

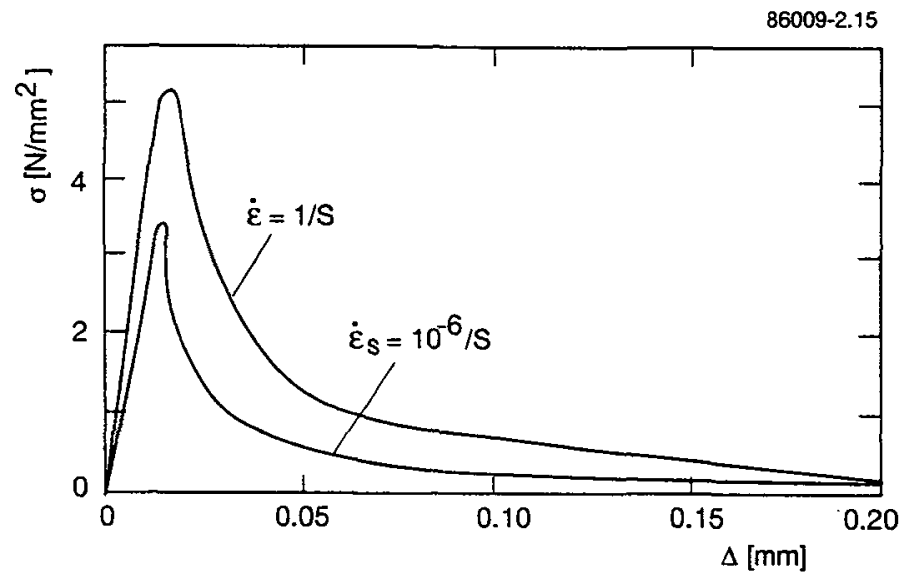

Figure 1 Rate effect on load-deformation curve for tension [5]

A difference in opinion emerges in the interpretation of the results. In the above mentioned investigations it was concluded from the test results that the fracture energy of concrete increases with the strain rate. The authors of this paper, however, doubted the correctness of this interpretation. The question did arise whether the increase in absorbed energy was not caused by structural instead of material response. Multiple cracking and inertia effects are two structural aspects which might be responsible for the increase in absorbed energy. In order to check this hypothesis, a research method was developed by TNO-PML and DUT, the potentiality of which lies in the combination of experiments and numerical simulation.

\section{EXPERIMENTS}

The experimental programme consisted of uniaxial impact tensile tests on U-notched and unnotched prismatic and cylindrical concrete specimens in a Split Hopkinson Bar apparatus. In the unnotched specimens multiple fracture zones could develop. In the notched specimens fracture was limited to a single zone thanks to the application of notches.

An overview of the performed experiments and the test programme is given in Table 1. Double edged notched prismatic specimens (A-series) were tested at a loading rate of approximately $15 \mathrm{GPa} / \mathrm{s}$. Circumferentially notched cylinders were tested at a quasi-static loading rate of $0.03 \mathrm{MPa} / \mathrm{s}$ (S-series) and a dynamic loading rate, between 19.7 and $24.0 \mathrm{MPa} / \mathrm{s}$ (D-series). All specimens had a height of $100 \mathrm{~mm}$. The unreduced cross section of the prismatic specimen was $50 \times 80 \mathrm{~mm}$ and the reduced cross section $(50-2 \mathrm{n}) \times 80$ $\mathrm{mm}$, where $n$ is the notch depth. The cylindrical specimen had a diameter of $74 \mathrm{~mm}$. The concrete had a maximum aggregate size of $8 \mathrm{~mm}$.

Table 1 The test series and test conditions

\begin{tabular}{|lllll|}
\hline Reduction in cross section & $0 \%$ & $10 \%$ & $20 \%$ & $28 \%$ \\
Notch depth [mm] & 0 & 2 & $4 / 5$ & 7 \\
Prism/mix A & & & A5 & A7 \\
Loading rate [GPa/s] & & 17.7 & 12.0 \\
& & & \\
Cylinder/mix A & D0 & D2 & D4 & \\
Loading rate [GPa/s] & 24.0 & 22.8 & 19.7 & \\
Cylinder/mix A & & S2 & S4 & \\
Loading rate [MPa/s] & & 0.03 & 0.03 & \\
\hline
\end{tabular}

The load-deformation-curves of the entire specimen and of the fracture zone could be obtained from the measurements. These load-deformation-curves are presented in Figures 2 and 3. The data about the deformation and fracture energy, that can be obtained from these load-deformation-curves, are presented in Table 2. 

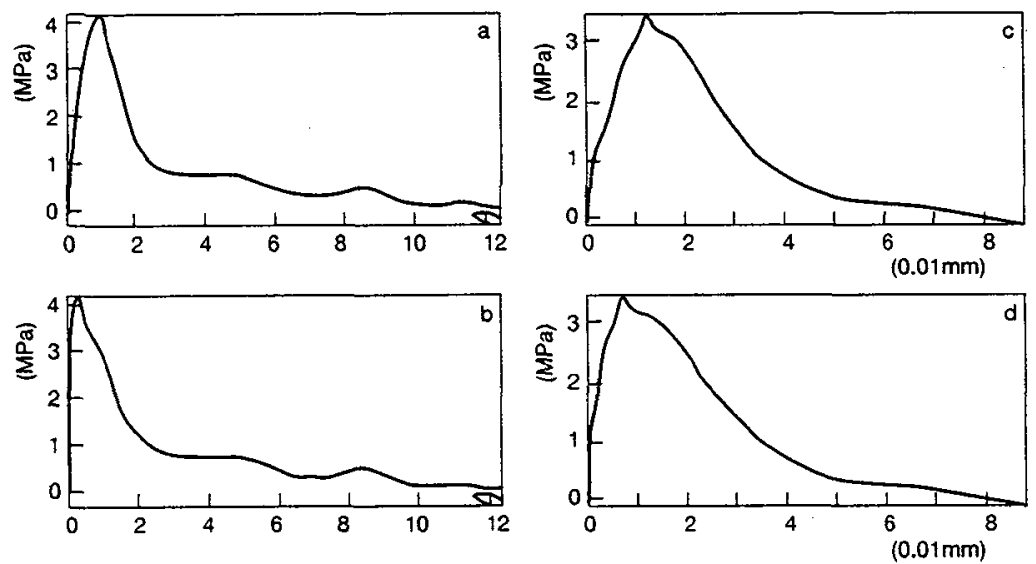
a. $\mathrm{A} 5, \partial_{\mathrm{tot}}$
b. A5, $\partial_{\mathrm{frac}}$
c. $\mathrm{A} 7, \partial_{\mathrm{tot}}$
d. A7, $\partial_{\mathrm{frac}}$

Figure 2 Load-deformation-curves of prismatic specimens
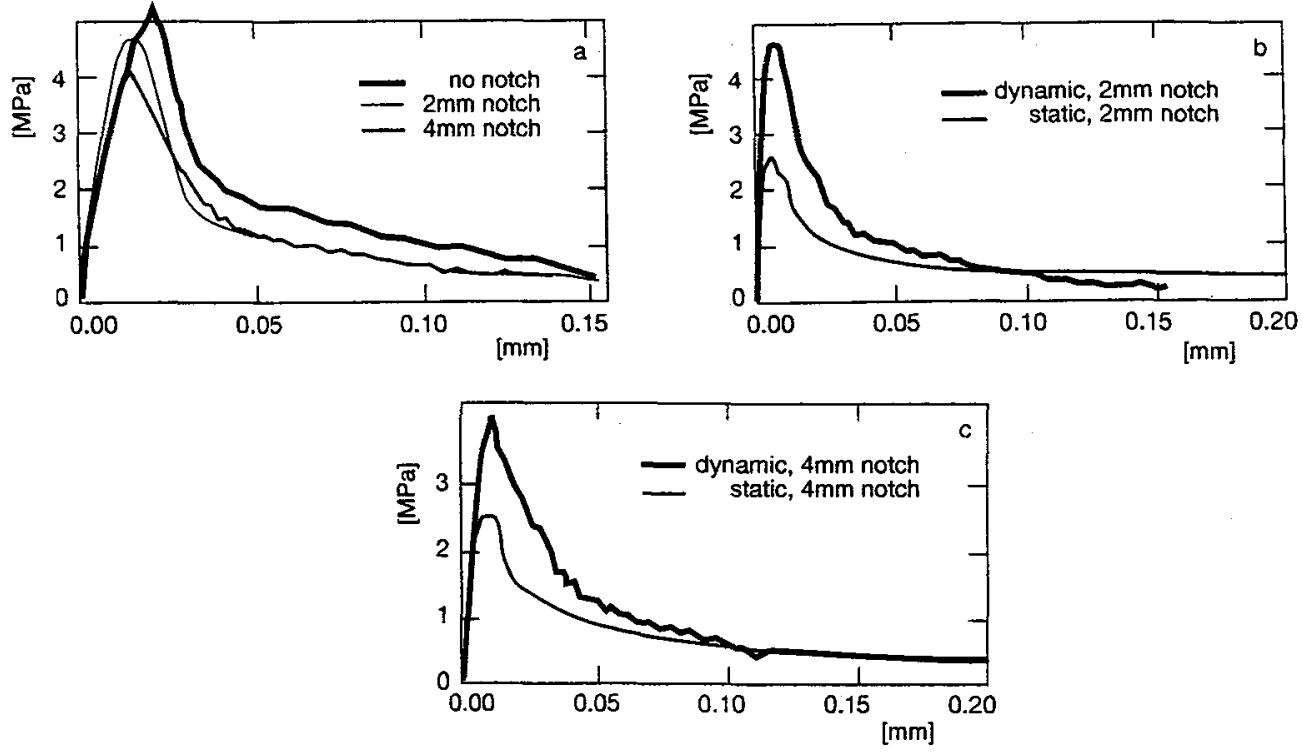

a. $\partial_{\text {tot }}$ comparison between unnotched and notched specimens under dynamic loading

b. $\partial_{\mathrm{frac}}, 2 \mathrm{~mm}$ notch, comparison between dynamic and static loading

c. Jfrac, $4 \mathrm{~mm}$ notch, comparison between dynamic and static loading

Figure 3 Load-deformation-curves of cylindrical specimens

Table 2 Strength, deformation and fracture energy

\begin{tabular}{|llllll|}
\hline & $\begin{array}{l}\mathrm{f}_{\mathrm{t}} \\
{[\mathrm{MPa}]}\end{array}$ & $\begin{array}{l}\partial_{\mathrm{f}, \text { top }} \\
{[\mu \mathrm{m}]}\end{array}$ & $\begin{array}{l}\partial_{\mathrm{f}, \text { tot }} \\
{[\mu \mathrm{m}]}\end{array}$ & $\begin{array}{l}\mathrm{G}_{\mathrm{f}, \text { top }} \\
{[\mathrm{N} / \mathrm{m}]}\end{array}$ & $\begin{array}{l}\mathrm{G}_{\mathrm{tot}} \\
{[\mathrm{N} / \mathrm{m}]}\end{array}$ \\
\hline A5 & 4.4 & 2.6 & 120 & 10.1 & 101 \\
A7 & 3.9 & 6.5 & 95 & 16.5 & 99 \\
D0 & 5.1 & - & 270 & - & 270 \\
D2 & 4.6 & 6.0 & 153 & 22 & 163 \\
D4 & 4.0 & 9.5 & 135 & 25 & 170 \\
S2 & 2.5 & 4.5 & $>200$ & 9.8 & 122 \\
S4 & 2.4 & 7.7 & $>200$ & 16.1 & 136 \\
\hline
\end{tabular}


Some observations can be made from the load-deformation-curves and the corresponding deformation data. The first two observations refer to the strength of the specimens and are therefore only briefly mentioned. More attention will be paid to observations with regard to the deformation and absorbed energy.

The expectation that the strength would increase with the loading rate was confirmed. The specimen strength in the dynamic tests was higher than in the static tests. This increase can be attributed to the changing geometry of the fracture plane and inertia effects on crack propagation (see model as described by Weerheijm [7]).

The strength of the specimen was reduced by the notch as can be seen from all series. This reduction in strength can be explained by a sensitivity for stress concentrations, which occur due to the applied notches.

The D-series show the effect of notches on the response of the specimen. In the unnotched specimens the location of the fracture zone was not fixed and multiple fracture occurred. This resulted in a considerable nonlinear prepeak deformation, a larger total deformation and a higher fracture energy.

Nonlinear prepeak deformation can also be observed in the notched specimens. The deeper the notch, the larger the prepeak deformation was. In these specimens the nonlinear prepeak deformation was not caused by multiple cracking but by the notches themselves. Because of stress concentrations at the notch the strength was reached locally and the specimen became nonlinear. Micro-cracking increased and enabled redistribution of stress before maximum strength, thanks to which failure was delayed, but not long enough to reach the material strength.

Where the application of a notch did make a difference for the fracture energy of the specimen, the depth of the notch did not show any influence on the fracture energy. The same specimens but with different notch depths (A5 and A7, D2 and D4) had approximately the same fracture energy. A higher energy absorption in the prepeak phase due to microcracking reflects itself in a lower residual energy absorption capacity in the softening phase.

A comparison with static tensile tests was made for the cylinders. The specimens in the dynamic tests had absorbed more energy than the statically tested specimens. Concluding now on base of this observation that the fracture energy indeed increases with strain rate, although not as much as had been concluded in the earlier investigations ([5], [6]), would be premature. The results are still obscured by inertia effects, since these cannot be eliminated in the experimental programme. In the next paragraph these inertia effects will be considered. With use of a numerical simulation it will be shown that and how inertia effects influence the energy data.

An unexpected result was the considerable difference between the energy absorbed in the A-series and in the D-series. This can be explained by one or a combination of the following three possible effects:

1 The fracture energy of the concrete of the prismatic specimens might have been less due to different hardening conditions. The prismatic specimens were stored in the test room whereas the cylinders were stored in a wet room. Eigenstresses due to differential drying might therefore have been more pronounced in the prisms and have reduced the fracture energy. On the other hand, the amount of free water in the cylinders was higher. From several studies (see [8] and [9]) it is known that the increase in strength with the loading rate is higher when there is more free water in the concrete. It has never been examined, but maybe free water has the same influence on the dynamic fracture energy.

2 Next to multiple cracking and inertia, the geometry and the experimental set-up might have been other structural parameters that influenced the response. It is known that the geometry of a specimen has an effect on its strength. Likewise, the geometry can have an influence on the deformation capacity and the fracture energy. This can be studied by numerical simulation.

3 The inertia effects in the postpeak behaviour might have been larger in the cylindrical specimen, in which the loading rate was higher. A clue for this effect is the longer tail in the postpeak part of the load-deformation-curve.

As will be shown in the next paragraph, the difference between both series diminishes when the above mentioned structural effects are taken into account.

\section{NUMERICAL SIMULATION}

The response measured in the experiments is influenced by structural effects as the geometry, the inertia of the specimen and the stiffness of the experimental set-up. For this reason the material parameters which determine the postpeak response cannot be derived directly from the experiments. A combination with a numerical analysis can overcome this problem.

Specimens A7 and D4 were chosen for numerical simulation. They are modelled with eight-noded elements, using a nine-point Gaussian integration scheme. Assuming a plane stress condition for the prismatic specimen, it was sufficient to analyse a plane section across the length of the specimen. Making use of the axi-symmetry for the cylinder, it sufficed to consider only a plane section of the specimen along its axis of symmetry. The finite element modelling of the experimental set-up is extensively described in [10].

The constitutive model was separated in a linear elastic model for the uncracked material and a softening model for the cracked concrete. No prepeak fracture is modelled. The constitutive softening model was formulated within the smeared crack concept [11]. In this concept the dissipated energy and the deformation 
of the failure zone is spread over a crack band. The power-law function of Moelands [12] was taken to describe the nonlinear postpeak behaviour.

The constitutive softening models were not the same. In the model for the prismatic specimen the size of the crack band was related to the element configuration and therefore the solution was mesh dependent. By the time the simulation of the test on the cylindrical specimen was carried out, much progress was made. The result could be kept objective with respect to the finite element size thanks to the introduction of a parameter which is dependent on the size of the fracture zone, the so-called crack band width $h$.

The input parameters in the model are presented in Table 3 . Here a dual approach was used. For the tensile strength we included the dynamic effect and for the fracture energy not. By taking the static value for the fracture energy, it was possible to analyse a possible increase of this material parameter due to rate effects.

Table 3 Input parameter for numerical model

\begin{tabular}{|lcc|}
\hline & $\mathrm{A} 7$ & $\mathrm{D} 4$ \\
\hline Young's modulus [GPa] & 40 & 40 \\
Poisson's ratio & 0.2 & 0.2 \\
Mass density of [kg/m3] & 2350 & 2400 \\
Tensile strength [MPa] & 4.9 & 5.2 \\
Fracture energy [N/m] & 100 & 125 \\
Shape factor softening curve & 0.3 & 0.31 \\
Crack band width [mm] & - & 2.67 \\
\hline
\end{tabular}

The results of the simulation are presented by the load-deformation-curves in figure 4 . For the A7-specimen two opposite sites were examined because of the occurrence of rotation in the prism.
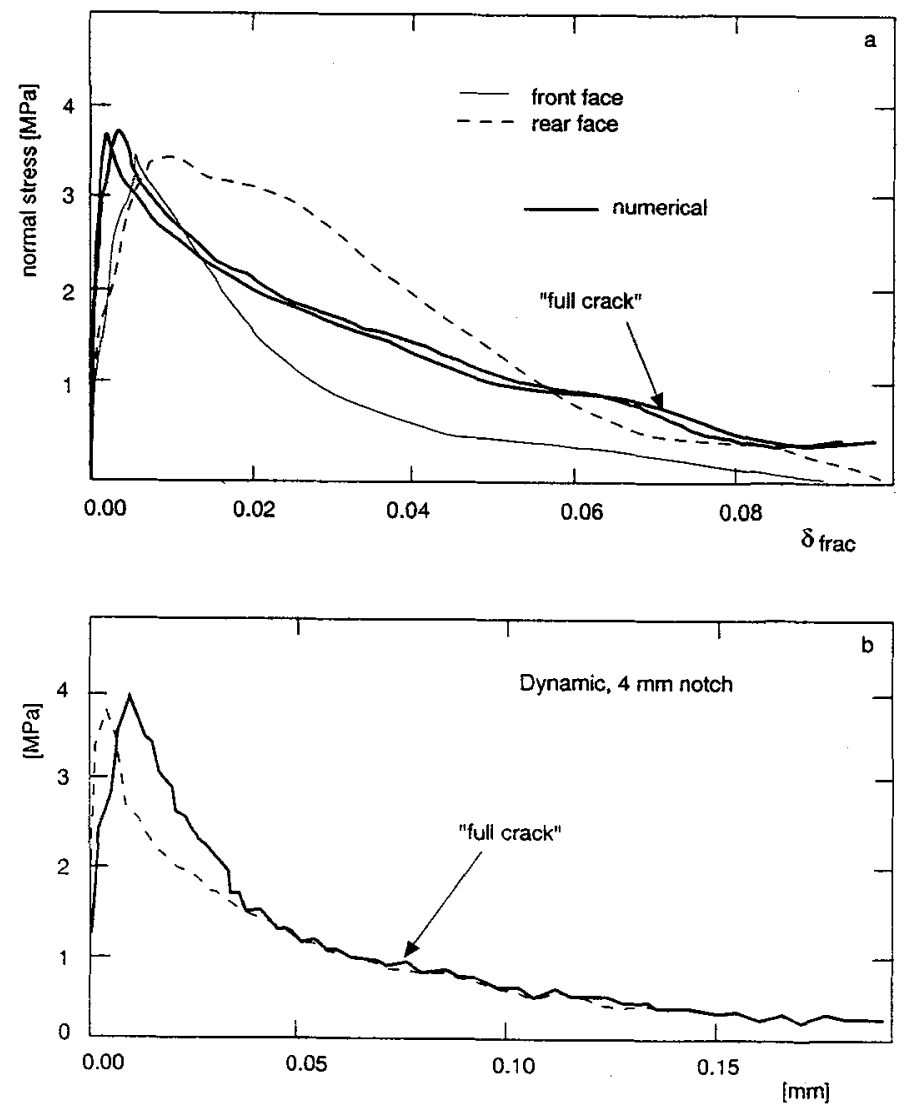

Figure 4 Comparison of experimental and numerical load-deformation-curve 
Two main conclusions can be drawn from the calculations. First, the inertia of the specimen contributed to the increase of the fracture energy in comparison to the static case. At a certain stage a full crack situation occurred, without the ability to transmit a force. Despite of the full crack the stress contribution to inertia was still present. This stress contribution lingered longer in the cylindrical specimen, which resulted in a higher increase in fracture energy.

Comparison of the calculated and measured load-deformation-curves shows good correspondence of the long tails, where inertia dominates the transmitted force. The main difference occurs just beyond the peak, which is mainly caused by not taking into account any prepeak cracking in the calculations. It can be concluded that the dynamic fracture energy does not differ considerably from the static fracture energy. For the cylindrical specimens the dynamic fracture energy was a little higher and for the prismatic specimens a little lower.

For a quantification of the various contributions to the fracture energy of inertia, geometry and material a more complete numerical study is necessary. With the present approach of a combination of experiments and numerical simulation this quantification should be possible and a proper material model should be derivable. At this stage, it is recommended to apply the static fracture energy value and the power-law function of Moelands [11] to present the softening branch for dynamic response calculations.

\section{CONCLUSIONS}

As a result of the research programme the following conclusions can be drawn.

- Deformation data in dynamic experiments are influenced by structural response. This has been demonstrated by the difference (40-50\%) in total deformation and fracture energy between unnotched and notched specimens and between cylindrical and prismatic specimens.

- The observed dynamic fracture energy of a specimen is larger than the material fracture energy because of inertia effects. These effects are responsible for the observed and calculated long tailed loaddeformation curves.

- The dynamic fracture energy is approximately the same as the static fracture energy.

- In order to obtain the best results currently possible, it is recommended to apply the static fracture energy in dynamic calculations.

\section{References}

[1] Reinhardt H.W., Concrete under impact loading, Tensile strength and bond, Heron, Vol. 27, No. 3, 1982

[2] Suaris W. and Shah S.P., Constitutive model for dynamic loading of concrete. Fracture Mechanics of Concrete, ed. F.H. Witteman, Elsevier Science Publisher B.V., Amsterdam, 1983

[3] Jensen J.J., Ductility of high strength concrete under special loading conditions, SINTEF Report, No STF65 A91011, Norway December 1990

[4] Zielinski A.J., Fracture of concrete and mortar under uniaxial impact tensile loading, Dissertation, Delft University of Technology, Delft, 1982.

[5] Körmeling H.A. and Reinhardt H.W., "Strain rate effects on steel fibre concrete in uniaxial tension", Int. Journal of Cement Composites and Lightweight Concrete, Vol. 9, No. 4, pp. 197-204, 1987

[6] Oh B.H., Fracture behavior of concrete under high rates of loading, Int. J. Eng. Fract. Mech., Vol 35 , no. $1 / 2 / 3,1990$, pp $327-332$

[7] Weerheijm J., Concrete under impact tensile loading and lateral compression, Dissertation, Delft University of Technology, Delft, 1992

[8] Rossi P., Toutlemonde F., Le Maou F., Boulay C. and Van Mier J.G.M., Effet de vitesse dans le comportement mécanique du béton, Cas de la traction directe, Bull. liaison Labo. P. et Ch. - 184 mars-avr. 1993 - Réf 3695

[9] Ross C.A., Tedesco J.N. and Kuennen S.T., Effects of Strain Rate on Concrete Strength, presented at the ACI 1992 Spring Conv., Washington, DC, March 1992, Accepted for publication in ACI Materials Journal

[10] Sluys L.J., Wave propagation, localisation and dispersion in softening solids, Dissertation, Delft University of Technology, Delft, 1992

[11] Borst R. de and Nauta P., Non-orthogonal cracks in a smeared finite element model, Eng. Comp., B 2(1), pp. 35-46, 1985

[12] Reinhardt H.W., Cornelissen H.A.W. and Hordijk D.A., Tensile tests and failure analysis of concrete, J. Struct. Engrg ASCE, 112(11), pp. 2462-2477, 1986 